\title{
PERFORMANCE OF A REAL-TIME SENSOR AND PROCESSING SYSTEM ON A HELICOPTER
}

\author{
F. Kurz, D. Rosenbaum, O. Meynberg, G. Mattyus, P. Reinartz \\ DLR, German Aerospace Center, 82234 Wessling, Germany - \\ (franz.kurz, Dominik.rosenbaum, oliver.meynberg, gellert.mattyus, peter.reinartz)@dlr.de
}

\section{ICWG I/Va}

KEY WORDS: real-time processing, sensor design, aerial camera, hazards

\begin{abstract}
:
A new optical real-time sensor system (4k system) on a helicopter is now ready to use for applications during disasters, mass events and traffic monitoring scenarios. The sensor was developed light-weighted, small with relatively cheap components in a pylon mounted sideward on a helicopter. The sensor architecture is finally a compromise between the required functionality, the development costs, the weight and the sensor size. Aboard processors are integrated in the 4k sensor system for orthophoto generation, for automatic traffic parameter extraction and for data downlinks. It is planned to add real-time processors for person detection and tracking, for DSM generation and for water detection. Equipped with the newest and most powerful off-the-shelf cameras available, a wide variety of viewing configurations with a frame rate of up to $12 \mathrm{~Hz}$ for the different applications is possible. Based on three cameras with $50 \mathrm{~mm}$ lenses which are looking in different directions, a maximal FOV of $104^{\circ}$ is reachable; with $100 \mathrm{~mm}$ lenses a ground sampling distance of $3.5 \mathrm{~cm}$ is possible at a flight height of $500 \mathrm{~m}$ above ground.

In this paper, we present the first data sets and describe the technical components of the sensor. The effect of vibrations of the helicopter on the GNSS/IMU accuracy and on the $4 \mathrm{k}$ video quality is analysed. It can be shown, that if the helicopter hoovers the rolling shutter effect affects the $4 \mathrm{k}$ video quality drastically. The GNSS/IMU error is higher than the specified limit, which is mainly caused by the vibrations on the helicopter and the insufficient vibrational absorbers on the sensor board.
\end{abstract}

\section{INTRODUCTION}

Helicopters are a valuable mean of transportation for security authorities and organisations (Gstaiger 2014). Although, sensors customized for the needs of the BOS and rescue forces exist, e.g. from FLIR, wide-area and real-time mapping sensors are not in use yet. The German Aerospace Center (DLR) makes now the first step towards a real-time mapping sensor by developing the first prototype of the so called $4 \mathrm{k}$ system with a certificate of airworthiness for DLR's BO105 helicopter. The name of the sensor is derived from the $4 \mathrm{k}$ video capability and is also a reference to the DLR $3 \mathrm{~K}$ and the $3 \mathrm{~K}+$ camera system (Kurz 2012). Figure 1 shows the $4 \mathrm{k}$ system mounted on the BO105 using an external cargo carrier weapon carrier mount as link between $4 \mathrm{k}$ system and helicopter fuselage.

In this paper, the system components, the technical and geometrical sensor properties are presented and discussed with special focus on the influence of the vibrations on the GNSS/IMU accuracies and on the quality of the $4 \mathrm{k}$ video stream.

\section{THE 4K SYSTEM}

The $4 \mathrm{k}$ system is designed weight-optimized, small, and relatively low-cost, but equipped with a full real-time image processing chain including a high-capacity data downlink to the ground station. Figure 2 shows the composition of the $4 \mathrm{k}$ system, which consists of three non-metric off-the-shelf cameras, a microwave datalink system including two antennas, three processing units and a GNSS/IMU system. Table 1 lists the properties of the most important system components.

The $4 \mathrm{k}$ system is certified for the BO105 helicopter and mounted on an external cargo carrier on the right side $10 \mathrm{~cm}$ above the helicopter skids. The platform and housing of the $4 \mathrm{k}$ system is decoupled from the helicopter vibrations by using four absorbers inside the system housing. These absorbers mainly decouple from the vibrations caused by the main rotor and the four rotor blades $(7 \mathrm{~Hz}, 28 \mathrm{~Hz})$. Additionally, the eigen frequency of the sensor structure should be far away from the main and spurious oscillations of the rotor to prevent damages to the system.

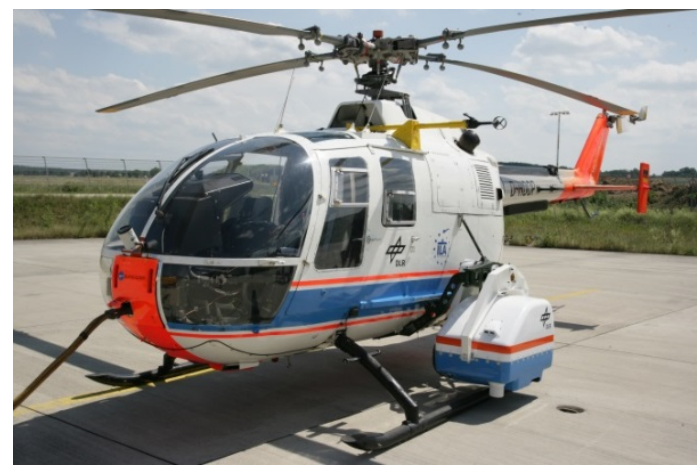

Figure 1. 4k system mounted on the helicopter BO-105

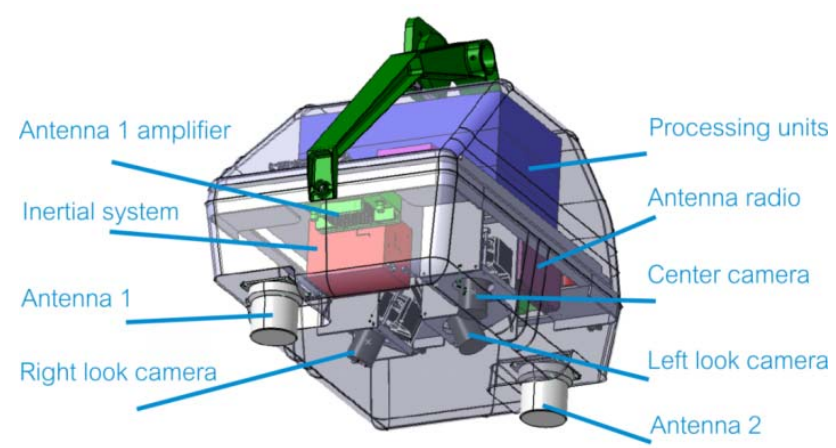

Figure 2. System components of the $4 \mathrm{k}$ system 
The system is connected to the $28 \mathrm{~V} / 35 \mathrm{~A}$ power supply of the helicopter and to the GPS antenna near the tail rotor. The system can be commanded from inside the helicopter via LAN or from the ground station via data link.

Three optical non-metric cameras are integrated in the sensor with different looking directions (see Figure 3). The latest camera generation from Canon EOS, two $1 \mathrm{D}-\mathrm{X}$ and one $1 \mathrm{D}-\mathrm{C}$, are installed on the platform, which each is capable of acquiring 17.9 MPix images with a frame rate of up to $14 \mathrm{~Hz}$.

Additionally, the Canon EOS $1 \mathrm{D}-\mathrm{C}$ is capable of acquiring $4 \mathrm{k}$ movies with a resolution of $4096 \times 2160$ pixels at $24 \mathrm{fps}$ and is installed in nadir direction. Table 2 lists the properties of the integrated Canon cameras.

Alternatively, four different lenses from Zeiss with $25 \mathrm{~mm}$, $35 \mathrm{~mm}, 50 \mathrm{~mm}$ and $100 \mathrm{~mm}$ focal length can be deployed, which leads to different ground sampling distances (GSD) and different footprint sizes on the ground. In Figure 4, the footprints of the most common camera and viewing configurations are visualized.

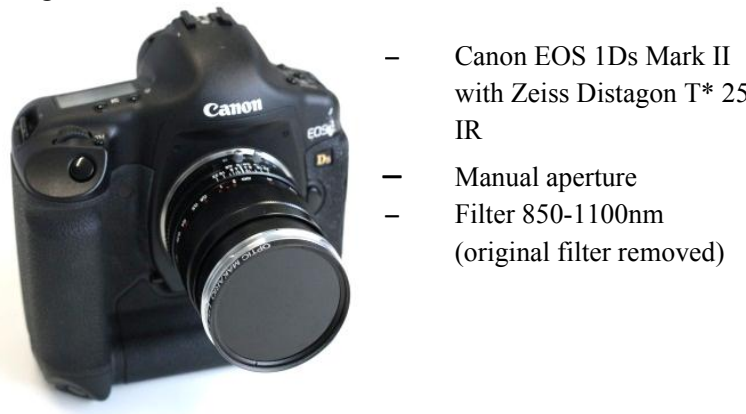

Figure 3. Properties of the near infrared sensitive camera
Additionally, one camera is modified to be sensitive in the near infrared region. Figure 3 shows the properties of the near infrared sensitive camera. The internal filter was removed and an $850 \mathrm{~nm}$ low pass filter was attached.

The camera is now sensitive to light from $850 \mathrm{~nm}$ to around $1100 \mathrm{~nm}$. This NIR sensitive band is mainly used for water detection in flood scenarios. The figure shows the Canon EOS 1Ds Mark II, whereas in the final version of the $4 \mathrm{k}$ system a NIR sensitive Canon EOS 1D-X will be installed.

In principle, the cameras of the $4 \mathrm{k}$ sensor are arranged to provide one nadir view and two oblique views. The oblique viewing angle is configurable freely with a maximum of $32^{\circ}$. There are two basic configurations.

In the first configuration the two oblique looking cameras have a small overlap in the nadir direction whereas the nadir looking camera, e.g. the NIR sensitive camera, is fully overlapping with the oblique looking cameras.

In the second configuration, all three cameras have a small overlap to reach the maximum FOV of $104^{\circ}$. Table 3 lists the viewing directions, the FOV, the coverages for two flight heights, and the GSD for each camera of the most common configurations.

A detailed discussion of the geometrical and radiometric properties of the cameras, the reached accuracies and a description of the real-time processing chain as it is installed at the $4 \mathrm{k}$ system is given in (Kurz 2012).

The real-time application scenarios for the $4 \mathrm{k}$ system are sketched (Kurz 2014).

\begin{tabular}{|c|c|c|c|c|}
\hline & Component & Size $[\mathrm{mm}]$ & Weight $[\mathrm{kg}]$ & Properties \\
\hline $2 \times$ & Microwave antenna $\left(\mathrm{SRS}^{1}\right)$ & $120 \times 120 \times 113$ & $2 \times 0.75$ & Bidirectional $\mathrm{C}$ band data link \\
\hline $1 \times$ & Network radio (SRS) & $58 \times 120 \times 230$ & 1.00 & rate, for distances up to $80 \mathrm{~km}$ \\
\hline $2 \times$ & Amplifier (SRS) & $78 \times 108 \times 220$ & $2 \times 1.60$ & line-of-sight. \\
\hline $3 \times$ & Canon EOS $1 \mathrm{D} \mathrm{X} / \mathrm{C}$ cameras & $158 \times 163.6 \times 82.7$ & $3 \times 1.34$ & See table 2 \\
\hline $3 \times$ & Zeiss lenses & $\varnothing 72$ length 65 & $3 \times 0.53$ & \\
\hline $1 \times$ & IMU (IGI ${ }^{2}$ Aerocontrol IId) & $200 \times 132 \times 137$ & 2.10 & Real-time GNSS/IMU measuring \\
\hline $1 \times$ & GPS/IMU processor (IGI) & $65 \times 140 \times 205$ & 1.80 & $0.1 \mathrm{~m}$, yaw $0.05^{\circ}$, roll $/$ pitch $0.01^{\circ}$ \\
\hline $1 x$ & Camera trigger box & $190 \times 110 \times 60$ & 0.6 & $\begin{array}{l}\text { Raspberry } \mathrm{Pi}^{3} \text { minicomputer with } \\
\text { programmed trigger intervals }\end{array}$ \\
\hline $3 x$ & PC unit & $430 \times 310 \times 90$ & 8.5 & \\
\hline $1 \times$ & Housing + plattform ... & $542 \times 869 \times 595$ & 40.1 & $\begin{array}{l}\text { Carbon fiber hull, aluminum } \\
\text { structure }\end{array}$ \\
\hline & & & $\Sigma 81.4$ & \\
\hline
\end{tabular}

Table 1. Properties of $4 \mathrm{k}$ system hardware components

\footnotetext{
${ }^{1}$ SRS: Schulze Radio Systems http://www.srsw.de

2 IGI: Ingenieur Gesellschaft für Interfaces mbH http://www.igi.eu

${ }^{3}$ Raspberry Pi: http://www.raspberrypi.org/
} 

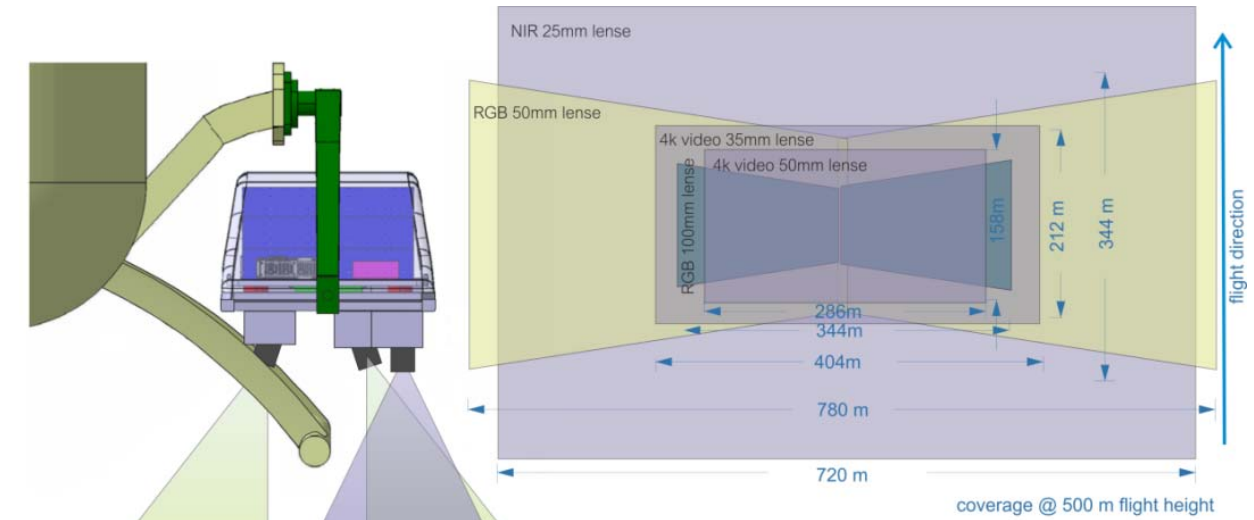

Viewing configuration and footprints of the $4 \mathrm{k}$ system with different configurations

\begin{tabular}{|c|c|c|}
\hline & Canon EOS 1D-X (left/right) & Canon EOS 1D-C (nadir) \\
\hline Lenses & $\begin{array}{l}\text { Zeiss Makro Planar 2/50, 2/100 } \\
\text { Zeiss Distagon T* } 35\end{array}$ & $\begin{array}{l}\text { Zeiss Makro Planar 2/50, 2/100 } \\
\text { Zeiss Distagon T*35 }\end{array}$ \\
\hline Sensor / Pixel size & Full frame CMOS / $6.944 \mu \mathrm{m}$ & Full frame CMOS / $6.944 \mu \mathrm{m}$ \\
\hline Image size & $\begin{array}{l}5184 \times 3456 \text { pixel, ratio } 3: 2 \\
(17.9 \text { MPix) }\end{array}$ & $\begin{array}{l}5184 \times 3456 \text { pixel, ratio } 3: 2 \\
(17.9 \text { MPix) }\end{array}$ \\
\hline & $\begin{array}{l}\text { JPEG (Canon L10-L1) } \\
\text { RAW (14Bit) }\end{array}$ & $\begin{array}{l}\text { JPEG (Canon L10-L1) } \\
\text { RAW (14Bit) }\end{array}$ \\
\hline $4 \mathrm{k}$ movies & & $\begin{array}{l}4096 \text { x } 2160 \text { pixel, ratio } 1.9: 1 \\
8.85 \text { MPix } \\
\text { max. } 24 \text { fps / } 4: 2: 2 \text { YUV } 8 \text { bit } \\
1.7 \text { Gbps (uncompressed) } \\
0.5 \text { Gbps (MJPEG compressed) }\end{array}$ \\
\hline ISO & $100-204800$ & $100-204800$ \\
\hline $\begin{array}{l}\text { Max. frame rate / } \\
\text { max. images }\end{array}$ & $14 \mathrm{fps} / 180$ images & $14 \mathrm{fps} / 180$ images \\
\hline Exposure time & $30 s-1 / 8000 s$ & $30 s-1 / 8000 s$ \\
\hline Data interface & LAN (EDSDK software interface) & LAN (EDSDK software interface) \\
\hline
\end{tabular}

Table 2. Properties of the $4 \mathrm{k}$ cameras

\begin{tabular}{|c|c|c|c|c|c|c|}
\hline & $\begin{array}{l}\text { Wide area RGB } \\
50 \mathrm{~mm} \text { lense }\end{array}$ & $\begin{array}{c}\text { RGB } \\
\text { 50mm lense }\end{array}$ & $\begin{array}{c}\text { RGB } \\
\text { 100mm lense }\end{array}$ & $\begin{array}{c}\text { NIR } \\
\text { 25mm lense }\end{array}$ & $\begin{array}{c}4 \mathrm{k} \text { video } \\
35 \mathrm{~mm} \text { lense }\end{array}$ & $\begin{array}{c}4 \mathrm{k} \text { video } \\
50 \mathrm{~mm} \text { lense }\end{array}$ \\
\hline $\begin{array}{l}\text { Viewing } \\
\text { directions }\end{array}$ & $\begin{array}{l}1 \times \text { Nadir } \\
2 \times \pm 32^{\circ}\end{array}$ & $2 \times \pm 19^{\circ}$ & $2 \times \pm 9^{\circ}$ & Nadir & Nadir & Nadir \\
\hline FOV & $\begin{array}{l} \pm 52^{\circ} \text { across } \\
\pm 13^{\circ} \text { along }\end{array}$ & $\begin{array}{l} \pm 38^{\circ} \text { across } \\
\pm 13^{\circ} \text { along }\end{array}$ & $\begin{array}{c} \pm 19^{\circ} \text { across } \\
\pm 7^{\circ} \text { along }\end{array}$ & $\begin{array}{l} \pm 36^{\circ} \text { across } \\
\pm 26^{\circ} \text { along }\end{array}$ & $\begin{array}{l} \pm 22^{\circ} \text { across } \\
\pm 12^{\circ} \text { along }\end{array}$ & $\begin{array}{c} \pm 16^{\circ} \text { across } \\
\pm 9^{\circ} \text { along }\end{array}$ \\
\hline $\begin{array}{l}\text { Coverage I' } \\
\text { GSD@500m }\end{array}$ & $\begin{array}{c}1280 \mathrm{~m} \times 230 \mathrm{~m} / \\
6.9 \mathrm{~cm} \text { nadir }\end{array}$ & $\begin{array}{c}780 \mathrm{~m} \times 230 \mathrm{~m} / \\
6.9 \mathrm{~cm} \text { nadir }\end{array}$ & $\begin{array}{c}344 \mathrm{~m} \times 122 \mathrm{~m} / \\
3.5 \mathrm{~cm} \text { nadir }\end{array}$ & $\begin{array}{l}720 \mathrm{~m} \times 480 \mathrm{~m} / \\
13.8 \mathrm{~cm} \text { nadir }\end{array}$ & $\begin{array}{c}404 \mathrm{~m} \times 212 \mathrm{~m} / \\
9.9 \mathrm{~cm} \text { nadir }\end{array}$ & $\begin{array}{c}286 \mathrm{~m} \times 158 \mathrm{~m} \\
6.9 \mathrm{~cm}\end{array}$ \\
\hline $\begin{array}{ll}\text { Coverage } \\
\text { GSD@1000m }\end{array}$ & $\begin{array}{c}2560 \mathrm{~m} \times 460 \mathrm{~m} / \\
13.8 \mathrm{~cm} \text { nadir }\end{array}$ & $\begin{array}{c}1560 \mathrm{~m} \times 460 \mathrm{~m} / \\
13.8 \mathrm{~cm} \text { nadir }\end{array}$ & $\begin{array}{c}688 \mathrm{~m} \times 244 \mathrm{~m} / \\
7.0 \mathrm{~cm} \text { nadir }\end{array}$ & $\begin{array}{l}1440 \mathrm{~m} \times 960 \mathrm{~m} / \\
27.6 \mathrm{~cm} \text { nadir }\end{array}$ & $\begin{array}{c}808 \mathrm{~m} \times 424 \mathrm{~m} / \\
19.8 \mathrm{~cm} \text { nadir }\end{array}$ & $\begin{array}{c}572 \mathrm{~m} \times 316 \mathrm{~m} \\
13.8 \mathrm{~cm}\end{array}$ \\
\hline
\end{tabular}

Table 3. Viewing geometry of six different sensor configurations 


\section{PERFORMANCE ANALYSIS}

The focus in the following performance analysis lies on the accuracy of the GNSS/IMU system in the presence of enormous vibrations of the helicopter and on the effect of these vibrations to the $4 \mathrm{k}$ video quality.

\subsection{Real-time GNSS/IMU}

The sensor including the IMU is decoupled from the helicopter with four absorbers, which are installed between the outer pylon
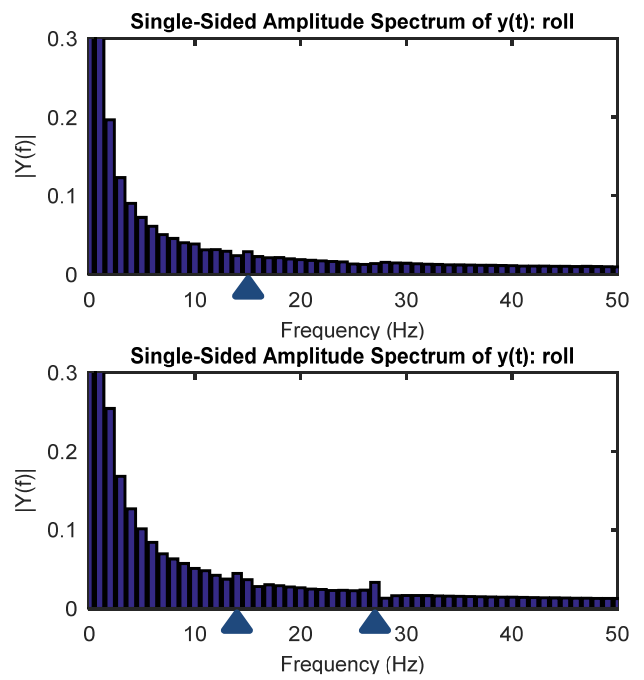

Figure 5. Single-sided amplitude spectrum of roll and pitch angle measured on the decoupled sensor board. Upper left and right: helicopter is hovering. Lower left and right: helicopter goes with standard speed $(\sim 60 \mathrm{~m} / \mathrm{s})$.

The spurious oscillation peaks of the rotor are marked.

It is expected that these vibrations have influence on the final accuracy of the GNSS/IMU system. Therefore, the reached position accuracies are analysed for the real-time and the postprocessing case. Figures 6 and 7 show exemplarily the theoretical accuracies of the position after a combined calculation of the position based on GPS and IMU measurements. In both cases, the reached accuracies are beyond the specified $0.1 \mathrm{~m}$, and even in the post-processing case the accuracies are not increased. A direct comparison of both cases should not be made, as they are based on different data sets.

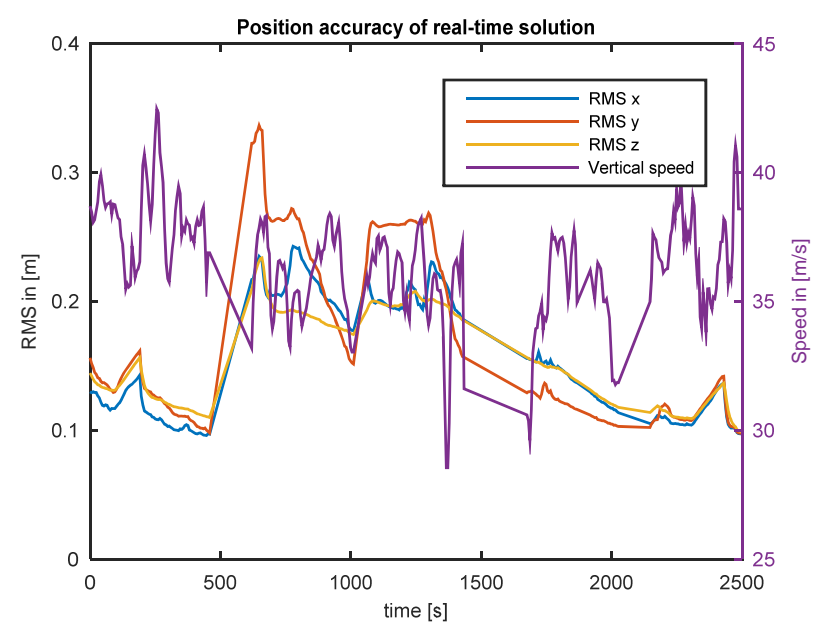

Figure 6: RMS of the sensor position in the real-time solution (left axis) and vertical speed of the helicopter (right axis)
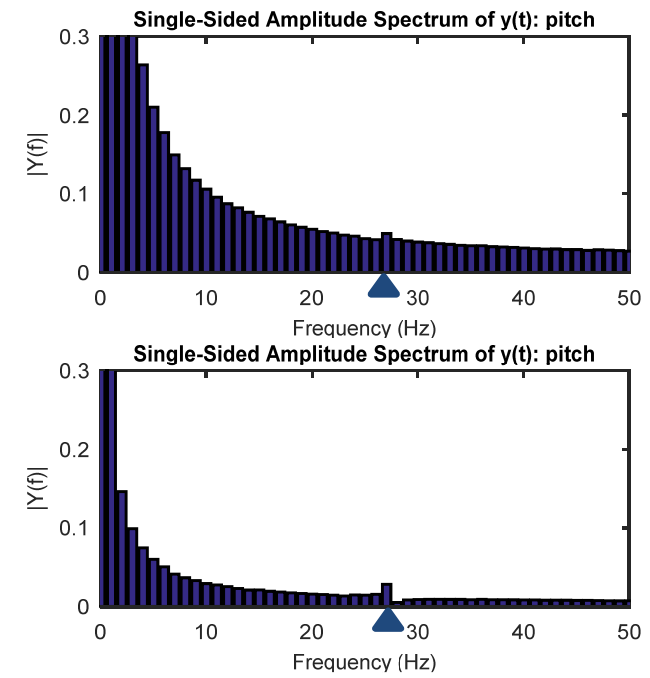

and the sensor board within the pylon. Figure 5 shows exemplarily the amplitude spectrum of roll and pitch angle measured on the decoupled sensor board.

As expected the vibrations are higher when the helicopter hoovers compared to the forward flying case. In some cases, the spurious oscillation peaks of the rotor blades appear in the amplitude spectrum which are located at around 14 and $28 \mathrm{~Hz}$ based on a rotational frequency of $7 \mathrm{~Hz}$. 


\section{$3.24 \mathrm{k}$ video}

As mentioned before, the Canon EOS 1D-C camera is capable to acquire $4 \mathrm{k}$ videos. Due to the vibrations of the helicopter, the rolling shutter effect has a great impact on the quality of the $4 \mathrm{k}$ video. The rolling shutter effect is caused by the line-by-line acquisition of the CMOS sensor in combination with movements of the imaged object which are happening during the time one single frame is captured. Transferred to the helicopter sensor it follows that the rolling shutter effect is caused by movements of the camera with a frequency higher than the frame rate of $24 \mathrm{fps}$. In Figure 8, the rolling shutter effect is visualized by showing the distortions between two consecutive $4 \mathrm{k}$ video frames. For this, tie points are matched, a projective transformation between two frames is calculated and then the differences after transformation are plotted as arrows. Clearly visible is a rolling shutter effect which is caused by the $28 \mathrm{~Hz}$ spurious oscillation of the rotor blades, as there is one movement in pitch direction in the upper third of the image and one movement in roll direction at the image bottom. The time difference (assuming that a frame is acquired within 1/24s) between two effects roughly corresponds to this $28 \mathrm{~Hz}$.

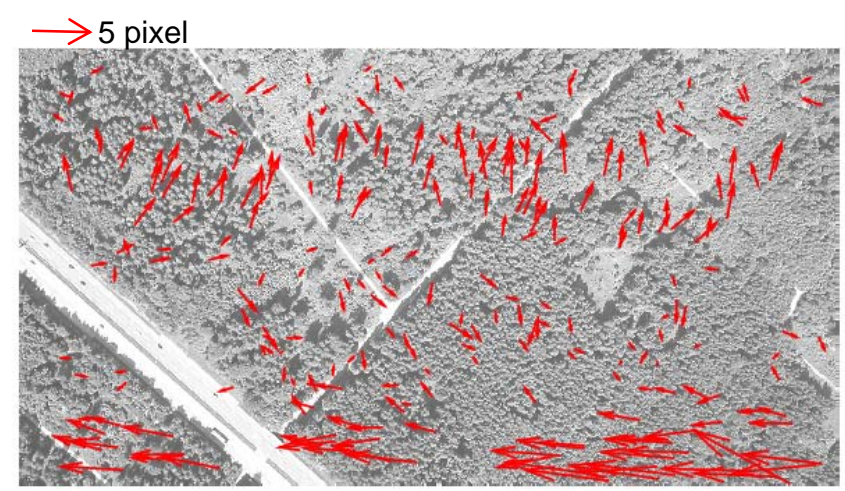

Figure 8: Image distortions between two consecutive $4 \mathrm{k}$ video frames if the helicopter hoovers. Arrows show the positional difference after projective transformation.

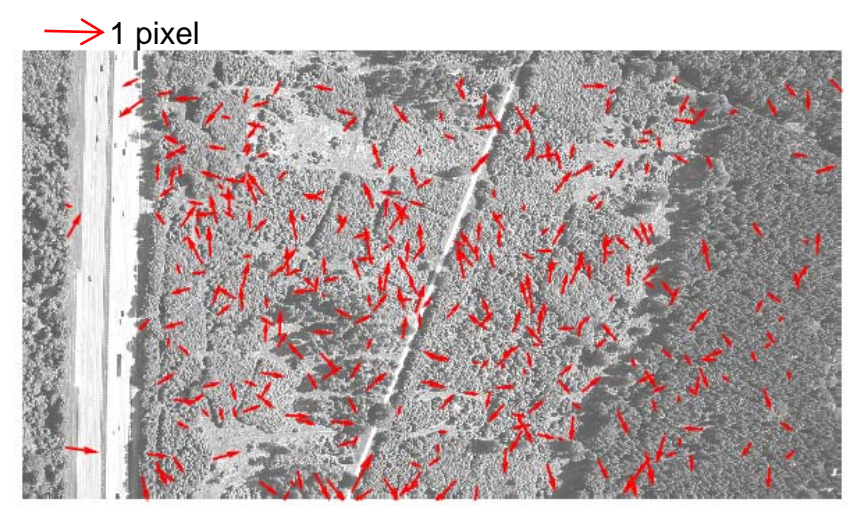

Figure 9: Image distortions between two consecutive 4k video frames if the helicopter goes with standard speed. Arrows show

the positional difference after projective transformation.

Figure 9 shows the image distortions between two consecutive $4 \mathrm{k}$ video frames but in difference to figure 8 with the helicopter going with standard speed. The remained distortions are all below 1 pixel, show no pattern, and are mainly caused to the changed viewing directions between two frames.

\section{DISCUSSION}

As presented in chapter 3, vibrations caused by the helicopter have great impact on the accuracy of the GNSS/IMU and on the quality of the $4 \mathrm{k}$ video stream. It was planned to reduce the vibrations by the absorbers which are installed on the sensor board. But first test flights have shown that these absorbers do not reduce the incoming vibrations sufficiently, at least not if the helicopter hoovers. The re-design of the sensor with better absorbers is one easy possibility to remedy the problem. The installation of a stabilization platform for the cameras would be another option but takes more efforts.

\subsection{Status}

In table 4 , the status of the processors which are planned for $4 \mathrm{k}$ sensor is listed. Operationally installed are the automatic traffic data extraction (Leitloff 2014) and the mapping processor. Ongoing research topics are real-time person data extraction and real-time 3D generation. All data products can be sent to ground-station in real-time, except the $4 \mathrm{k}$ video stream.

\begin{tabular}{|l|l|l|}
\hline & $\begin{array}{l}\text { real-time } \\
\text { processor }\end{array}$ & $\begin{array}{l}\text { downlink } \\
\text { capability }\end{array}$ \\
\hline 4k video & $x^{* *}$ & $x^{*}$ \\
\hline $\begin{array}{l}\text { Traffic data } \\
\text { extraction }\end{array}$ & $\checkmark$ & $\checkmark$ \\
\hline $\begin{array}{l}\text { Person data } \\
\text { extraction }\end{array}$ & $x^{* *}$ & $\checkmark$ \\
\hline Mapping & $\checkmark(0.5 \mathrm{fps})$ & $\checkmark(0.5 \mathrm{fps})$ \\
\hline 3D Mapping & $x^{* *}$ & $\checkmark$ \\
\hline
\end{tabular}

* Possible with optical data link (Moll 2013)

** Ongoing research

Table 4. Status of installed processors and downlink capability

\section{REFERENCES}

Gstaiger, V., Kurz, F., Hohloch, M., 2014: VABENE++ multisensor approach to support crisis management. In: International Disaster and Risk Conference (IDRC), 283-286. Global Risk Forum GRF Davos. 5th International Disaster and Risk Conference IDRC 2014, 24.-28. Aug. 2014, Davos, Schweiz.

Kurz, F., Türmer, S., Meynberg, O., Rosenbaum, D., Runge, H., Reinartz, P., 2012: Low-cost optical Camera System for realtime Mapping Applications. Photogrammetrie Fernerkundung Geoinformation, 2012 (2), 159-176. DOI: 10.1127/1432$8364 / 2012 / 0109$. ISSN 1432-8364.

Kurz, F., Rosenbaum, D., Meynberg, D., Mattyus, G., 2014: Real-time mapping from a helicopter with a new optical sensor system. In: Publikationen der Deutschen Gesellschaft für Photogrammetrie, Fernerkundung und Geoinformation e.V., 23, 1-8. DFG. 34. Wissenschaftlich-Technische Jahrestagung der DGPF, 26.-28. März 2014, Hamburg. ISSN 0942-2870

Leitloff, J., Rosenbaum, D., Kurz, F., Meynberg, O., Reinartz, P., 2014: An operational system for estimating road traffic information from aerial images. In: Remote Sensing, MDPI. In review.

Moll, F., 2013: Free-space laser system for secure air-toground quantum communications. SPIE Newsroom. DOI: 10.1117/2.1201311.005189. ISSN 1818-2259. 